\title{
Fine Particulate Air Pollution and Hospital Admissions for Chronic Obstructive Pulmonary Disease: A Case-Crossover Study in Taipei
}

\author{
Shang-Shyue Tsai ${ }^{1}$, Chih-Ching Chang ${ }^{2}$ and Chun-Yuh Yang ${ }^{3,4, *}$
}

1 Department of Healthcare Administration, I-Shou University, Kaohsiung 824, Taiwan;

E-Mail: sionghak@isu.edu.tw

2 Department of Environmental and Occupational Health, National Cheng Kung University, Tainan 701, Taiwan; E-Mail: chang3@mail.ncku.edu.tw

3 Department of Public Health, College of Health Sciences, Kaohsiung Medical University, Kaohsiung 807, Taiwan

4 Division of Environmental Health and Occupational Medicine, National Health Research Institute, Miaoli 350, Taiwan

* Author to whom correspondence should be addressed; E-Mail: chunyuh@kmu.edu.tw; Tel.: +886-7-312-1101 (ext. 2141); Fax: +886-7-311-0811.

Received: 4 September 2013; in revised form: 31 October 2013 / Accepted: 5 November 2013 / Published: 11 November 2013

\begin{abstract}
We undertook this study to investigate whether there is an association between atmospheric fine particles $\left(\mathrm{PM}_{2.5}\right)$ levels and inpatient admissions for chronic obstructive pulmonary disease (COPD) in Taipei, Taiwan. Data on inpatient admissions for COPD and ambient on air pollution levels in Taipei were obtained for years 2006 to 2010. We estimated the relative risk of inpatient admissions for COPD using a case-crossover design with the following control variables: weather measures, day of the week, seasonality, and long-term time trends. For the single-pollutant model (not controlling for other atmospheric pollutants), COPD admissions were significantly and positively associated with higher $\mathrm{PM}_{2.5}$ levels during both warm days $\left(>23{ }^{\circ} \mathrm{C}\right)$ and cool days $\left(<23{ }^{\circ} \mathrm{C}\right)$, with an interquartile range increase of $12 \%(95 \% \mathrm{CI}=8-16 \%)$ and $3 \%(95 \% \mathrm{CI}$ $=0-7 \%)$ in COPD admissions, respectively. In the two-pollutant models, $\mathrm{PM}_{2.5}$ remained significant even controlling for $\mathrm{SO}_{2}$ or $\mathrm{O}_{3}$ on both warm and cool days. Taken as a whole, our study demonstrates that higher levels of $\mathrm{PM}_{2.5}$ may increase the risk of inpatient admissions for COPD.
\end{abstract}


Keywords: fine particulate; air pollution; COPD; case-crossover; hospital admissions

\section{Introduction}

Over the past decade, many epidemiologic studies demonstrated positive associations between ambient levels of airborne particulate matter (PM) (generally measured as PM with an aerodynamic diameter $<10$ um $\left(\mathrm{PM}_{10}\right)$ ) increased mortality [1-7] and hospital admissions or emergency room (ER) visits for cardiovascular and respiratory morbidity [8-12]. The evidence on adverse effects of PM air pollution on public health has led to more stringent standards for levels of PM in outdoor air in the USA and in other countries [13,14].

While previous studies have primarily used $\mathrm{PM}_{10}$ as an exposure indicator, fine particles (defined as $\mathrm{PM}$ with an aerodynamic diameter $<2.5 \mathrm{um} ; \mathrm{PM}_{2.5}$ ) have become a greater health and regulatory concern due to epidemiologic studies suggesting that $\mathrm{PM}_{2.5}$ might exert greater toxicity than larger particles [15-18]. It is now generally accepted that $\mathrm{PM}_{2.5}$ are more harmful for health than larger particles $\left(\mathrm{PM}_{10}\right)$ because $\mathrm{PM}_{2.5}$ can be inhaled more deeply into the lungs and offer a greater surface area and hence potentially larger concentrations of adsorbed or condensed toxic air pollutants per unit mass $[19,20]$. It is for this reason exactly that the World Health Organization (WHO) recommends using $\mathrm{PM}_{2.5}$ instead of $\mathrm{PM}_{10}$ concentrations as indicators of air quality [6].

Relatively few epidemiologic studies have been undertaken which specifically address the health effects of $\mathrm{PM}_{2.5}$ due to lack of $\mathrm{PM}_{2.5}$ monitoring data [21]. Considerable attention has been focused on all respiratory admissions [17,21-25], possibly combining outcomes with different sensitivities to air pollution and different lags between exposure and hospitalization [26]. Several studies investigated the relationship between $\mathrm{PM}_{2.5}$ and hospital admissions (or ER visits) for chronic obstructive pulmonary disease (COPD) [13,23,27-30]. These studies were conducted principally in North America and European cities, so the findings may not be generalized to Taiwan, where the air pollutant mixtures may potentially be quite different.

There is a substantial number of epidemiological studies in Taiwan reporting associations between mortality/morbidity with ambient $\mathrm{PM}_{10}$ levels [31-36], but only a limited number of studies evaluating associations with $\mathrm{PM}_{2.5}$ levels, due primarily to the lack of monitoring data [37-41].

Our primary objective was to examine the short-term impact of $\mathrm{PM}_{2.5}$ levels on daily inpatient admissions for COPD among residents of Taipei, the largest city in Taiwan, using over 5 years of observations from 2006-2010, and a case-crossover design.

\section{Materials and Methods}

\subsection{Taipei City}

This study examined daily variations in hospital admissions for COPD in relation to $\mathrm{PM}_{2.5}$ levels in Taipei for the 5-year period from 2006 through 2010. Taipei is the largest metropolitan city in Taiwan with a population of approximately 2.64 million located in northern Taiwan. The major air pollution source is automobile exhaust emission. Taipei has a subtropical climate, with an annual average 
temperature of $23{ }^{\circ} \mathrm{C}$. (the months with a mean temperature below $23{ }^{\circ} \mathrm{C}$ are from November to April and May to October are the months with a mean temperature above $23{ }^{\circ} \mathrm{C}$ ).

\subsection{Hospital Admission Data}

The National Health Insurance (NHI) Program, which provides compulsory universal health insurance, was implemented in Taiwan on 1 March 1995. Under the NHI, 98\% of the island's population receives all forms of health care services including out-patient services, in-patient care, Chinese medicine, dental care, childbirth services, physical therapy, preventive health care, home care, and rehabilitation for chronic mental illness. Most medical providers (93\%) were under contract with the Bureau of NHI (BNHI), and those not under contract provide fewer health services. More than $96 \%$ of the population with insurance coverage through the NHI utilized health services at least one time at contracted medical institutions.

Data in electronic format on daily clinic visits or hospital admissions can be obtained for each contracted medical institution. In order to be reimbursed, all medical institutions must submit their claims for billable medical services on a standardized electronic form, which includes data elements such as the date of admission and discharge, patient identification number, gender, birthday, and the ICD-9-CM diagnostic code for each admission. Therefore, the information from the NHI database appears to be sufficiently complete, reliable, and accurate for use in epidemiological studies. Daily counts of hospital admissions with a primary diagnosis of COPD (International Classification of Diseases, 9th revision [ICD-9] codes 490, 492, 494, and 496) were extracted from the medical insurance files for the period 2006-2010.

\section{3. $P M_{2.5}$ and Meteorological Data}

Six air quality monitoring stations were established in Taipei city by the Taiwanese Environmental Protection Administration (EPA), a central governmental agency in 1994. The monitoring stations were fully automated and routinely monitored five "criteria" pollutants including sulfur dioxide $\left(\mathrm{SO}_{2}\right)$ (by ultraviolet fluorescence); particulate matter $\left(\mathrm{PM}_{10}\right)$ (by beta-ray absorption); nitrogen dioxide $\left(\mathrm{NO}_{2}\right)$ (by ultraviolet fluorescence), carbon monoxide (CO) (by nondispersive infrared photometry), and ozone $\left(\mathrm{O}_{3}\right)$ (by ultraviolet photometry) levels. However, $\mathrm{PM}_{2.5}$ was not regularly monitored. $\mathrm{PM}_{2.5}$ concentrations in Taiwan were measured continuously since $2006 . \mathrm{PM}_{2.5}$ was measured using tapered element oscillating microbalance method samplers. The availability of the monitoring network for $\mathrm{PM}_{2.5}$ provided an opportunity to investigate the impact of $\mathrm{PM}_{2.5}$ on hospital adsmissions for COPD. For each day, hourly air pollution data were obtained for all of the monitoring stations. After calculating the hourly mean of each pollutant from the six stations, the $24 \mathrm{~h}$ average levels of these pollutants were computed. Daily information on mean temperature and mean humidity was provided by the Taipei Observatory of the Central Weather Bureau. 


\subsection{Statistics}

Data were analyzed using the case-crossover technique [42-44]. This design is an alternative to Poisson time series regression models for studying the short-term effects attributed to air pollutants [45]. In general, the case-crossover design and the time-series approach yielded almost identical results [46-48].

For our case-crossover analysis, we adopted a time-stratified approach [45]. We stratified time into separate months in order to select referent days falling on the same day of the week within the same month as the index day. Air pollution levels during the case period were compared with exposures occurring on all referent days. This time-stratified referent selection scheme minimizes bias due to non-stationarity of air pollution time-series data [49-51]. The results of previous studies indicated that increased number of hospital admissions were associated with higher air pollutant levels on the same day or the previous two days [52]. Longer lag times have rarely been described. Thus the cumulative lag period up to 2 previous days (i.e.; the average air pollutant levels of the same and previous 2 days) was used. Because pollutants vary considerably by season, especially $\mathrm{O}_{3}$ and particles, seasonal interactions between $\mathrm{PM}_{2.5}$ and hospital admissions have often been reported. However, previous studies were conducted mostly in countries where the climates are substantially different from that in Taipei [31,35], which has a subtropical climate with no apparent 4-season cycle. Hence in this study the potential interactions of seasonality on the effects of $\mathrm{PM}_{2.5}$ was not considered; but temperature was used instead. The adverse health effects of each air pollutant were examined for the "warm" days (days with a mean temperature above $23^{\circ} \mathrm{C}$ ) and "cool" days (days with a mean temperature below $23{ }^{\circ} \mathrm{C}$ ) separately.

The associations between hospital admissions for COPD and levels of $\mathrm{PM}_{2.5}$ were estimated using the odds ratio (OR) and their 95\% confidence intervals (CI) which were produced using conditional logistic regression with weights equal to the number of hospital admissions on that day. All statistical analyses were performed using the SAS package (version 9.2; SAS Institute, Inc.; Cary, NC, USA). Both single-pollutant models and multi-pollutant models were fitted with a different combination of pollutants (up to two pollutants per model) to assess the stability of the effect of $\mathrm{PM}_{2.5}$. Exposure levels to air pollutants were entered into the models as continuous variables. Meteorologic variables such as daily average temperature and humidity on the same day, which might play a confounding role, were included in the model. In all analyses, we modeled the mean temperature at lag 0 as a quadratic function, mean humidity at lag 0 , and pollutants as a linear function of the 3-day moving average of current and previous 2 days concentrations (lag 0-2). Inclusion of barometric pressure did not markedly change the effect estimates and therefore was not considered in the final model. OR were calculated for the interquartile difference (IQR, between the 25th and the 75th percentile) for $\mathrm{PM}_{2.5}$, as observed during the study period.

\section{Results and Discussion}

During the 5 years of the study, there were a total of 22,424 hospital admissions for COPD for the 47 hospitals in Taipei city. The descriptive statistics for admissions and corresponding environmental data are shown in Table 1. There was an average of 12.28 daily hospital admissions for COPD in the city over the study period. 
Pearson's correlation coefficients among the air pollutants are presented in Table 2. Significant cross-correlations among pollutants were observed, especially between $\mathrm{PM}_{10}$ and $\mathrm{PM}_{2.5}$ $(r=0.78), \mathrm{PM}_{2.5}$ and $\mathrm{SO}_{2}(r=0.61), \mathrm{PM}_{2.5}$ and $\mathrm{NO}_{2}(r=0.54), \mathrm{PM}_{2.5}$ and $\mathrm{CO}(r=0.54), \mathrm{SO}_{2}$ and $\mathrm{NO}_{2}$ $(r=0.52), \mathrm{SO}_{2}$ and $\mathrm{CO}(r=0.50)$, and between $\mathrm{NO}_{2}$ and $\mathrm{CO}(r=0.89)$.

Table 3 shows the effect estimates of $\mathrm{PM}_{2.5}$ on hospital admissions for COPD in single-pollutant models and two-pollutant models. For the single pollutant model (without adjustment for other pollutants), increased admissions for COPD were significantly associated with $\mathrm{PM}_{2.5}$ both on warm $\left(>23{ }^{\circ} \mathrm{C}\right)$ and cool days $\left(<23{ }^{\circ} \mathrm{C}\right)$, with an IQR increase associated with a $12 \%(95 \% \mathrm{CI}=8-16 \%)$ and $3 \%(95 \% \mathrm{CI}=0-7 \%)$ increase in COPD admissions, respectively. In two-pollutant models, $\mathrm{PM}_{2.5}$ remained significant after the inclusion of $\mathrm{SO}_{2}$ or $\mathrm{O}_{3}$ both on warm and cool days.

This study is one of the few that investigated the association between exposure to $\mathrm{PM}_{2.5}$ and hospital admissions for COPD and is the first in Asia. Data demonstrated that the levels of $\mathrm{PM}_{2.5}$ were positively associated with increases in the daily number of hospitalizations for COPD after inclusion of $\mathrm{SO}_{2}$ or $\mathrm{O}_{3}$ both on warm and cool days. The observed effects of $\mathrm{PM}_{2.5}$ were not maintained in the presence of $\mathrm{NO}_{2}$ or $\mathrm{CO}$. It is possible that the effect of $\mathrm{PM}_{2.5}$ might have been masked by those of $\mathrm{NO}_{2}$ and $\mathrm{CO}$.

Studies on the effect of $\mathrm{PM}_{2.5}$ on COPD admissions are rare. Belleudi et al. conducted a study in Rome, and found no evidence of an association between COPD admissions and exposure to $\mathrm{PM}_{2.5}$ [28]. A study in Helsinki by Halonen et al. [23] reported a 5.3\% increase in the risk of COPD admission per $10 \mathrm{ug} / \mathrm{m}^{3}$ increase in the level of $\mathrm{PM}_{2.5}$ which is similar to their study results on COPD ER visits $(4.6 \%$ for $\left.10 \mathrm{ug} / \mathrm{m}^{3} \mathrm{PM}_{2.5}\right)$ [27]. Dominici et al. reported a $1.61 \%(95 \% \mathrm{CI}=0.56-2.66 \%)$ increase in hospitalization for COPD per $10 \mathrm{ug} / \mathrm{m}^{3}$ increase in $\mathrm{PM}_{2.5}$ level [13]. In this study, we found a $6.87 \%$ (which corresponds to $12 \%$ increase per IQR increment) and $1.72 \%$ (which corresponds to $3 \%$ increase per IQR increment) increase in hospitalization for COPD per $10 \mathrm{ug} / \mathrm{m}^{3}$ increment in the 3 day moving average (lag 2) concentrations of $\mathrm{PM}_{2.5}$ for warm days and cool days, respectively.

In our study, effects were observed on both warm and cool days, but they were larger on warm days (effect modification). We were able to confirm that PM effects vary by season [17,22]. The observed seasonal variation in effect estimates could be explained by variation in exposure patterns. People in Taipei are more likely to go outdoors and open the windows in the warm season than in cool season (higher exposure); thus, monitored $\mathrm{PM}_{2.5}$ concentrations may be closer to personal exposure to $\mathrm{PM}_{2.5}$ in the warm season than in the cool season (better exposure assessment). The fact may attenuate the $\mathrm{PM}_{2.5}$ effect in the cool season. On the other hand, seasonal differences in air pollution mixture may also affect the effect estimates. Furthermore, compared with other studies in developed countries, our study found larger effect estimates per unit increase of $\mathrm{PM}_{2.5}$. One potential explanation for this discrepancy is that most published studies only demonstrated straightforward pooled effect estimates (lack of effect estimates stratified by season). This may conceal inherent differences between different climates and air pollution mixtures. Variations in seasonal and regional effect estimates may in part result from differences in the chemical composition of $\mathrm{PM}_{2.5}$ [22]. Nevertheless, the seasonal pattern of air pollution health effects need to be further investigated.

The most common and consistent associations between air pollutants and hospital admissions for respiratory disease were found with PM [53]. A significant association was found between $\mathrm{PM}_{2.5}$ exposure and COPD admissions in this study. This finding is in agreement with previous studies [13,23,27]. 
Some pathophysiological hypotheses have been proposed to explain the association between short-term effects of $\mathrm{PM}_{2.5}$ and COPD admissions. Researchers have suggested that $\mathrm{PM}_{2.5}$ levels represent the effective toxic fraction of PM, because PM increase and sustain oxidative stress both on the entire respiratory tract and on the systemic level, where oxidative stress induces inflammation [54,55]. In the lungs, PM may cause inflammation and thereby aggravate an underlying lung disease, thereby reducing the efficacy of lung-defense mechanisms [13]. Animal studies have shown an increased vulnerability to PM in animal with cardiopulmonary disease [56], and exacerbations of ongoing pneumococcal infection after exposure to concentrated ambient $\mathrm{PM}_{2.5}$ [57].

Numerous studies have documented an association between air pollution and increased hospital admissions in cities worldwide. Major $\mathrm{PM}_{2.5}$ components vary geographically seasonally, but typically include ammonium sulfate and nitrate, elemental carbon, carbonaceous species, carbonates, metals, and water [24,58]. Despite the volume of research on the subject, the relative toxicity of different components of $\mathrm{PM}_{2.5}$ remains unanswered but toxicity is likely to vary between components [58].

Maclure proposed the case-crossover study design as a way to study the influence of transient, intermittent exposures on the subsequent risk of uncommon acute-onset events shortly after exposure [42]. This design offers the ability to control many confounders by design rather than by statistical modelling. This design is an adaptation of the case-control study in which each case serves as his or her own referent. Therefore time-invariant subject-specific variables such as gender, age, underlying chronic disease, or other individual-level characteristics do not act as confounders. In addition, time-stratified approach [43] was found to be effective in controlling for seasonality, time trends, and chronic and slowly varying potential confounders [49-51]. In general, the case-crossover design and the general additive model (GAM) approach, which has been the analytic method of choice for studying short-term adverse effects of air pollution since 1990 [59], produced almost identical results [46-48].

For a factor to confound the relationship between $\mathrm{PM}_{2.5}$ levels and admissions for COPD it needs to be correlated with both variables. It is unlikely that smoking and other indoor pollutants confound the present association since day to day variations in indoor emissions, including smoking may not be correlated with $\mathrm{PM}_{2.5}$ air pollution.

Exposure measurement error is a common concern in environmental epidemiology. $\mathrm{PM}_{2.5}$ levels were assigned from fixed, outdoor monitoring stations to individuals to estimate exposure (assuming that exposure was homogeneous over all the studied area). Exposure measurement errors resulting from differences between the population-average exposure and ambient $\mathrm{PM}_{2.5}$ levels are not avoidable. This kind of measurement error will result in nondifferential misclassification. However, this exposure misclassification is likely to cause a bias toward the null and lead to underestimates of pollutant effects $[52,60]$.

Our study population is homogenous in terms of race compared with populations in other cities. This study was conducted in a subtropical city. These facts may restrict somewhat the generalizability of these findings to other locations with different meteorological and racial characteristics. Further, behavior such as air conditioning usage or time spent outdoors may affect personal exposures. This might affect the magnitude of the observed associations compared with other geographical locations. 
Table 1. Distribution of daily COPD admissions, weather, and air pollution variables in Taipei, Taiwan, 2006-2010.

\begin{tabular}{lccccccc}
\hline \multirow{2}{*}{ Variable a } & \multirow{2}{*}{ Min } & \multicolumn{3}{c}{ Percentile } & \multirow{2}{*}{ Max } & Mean & \multirow{2}{*}{ Days } \\
\cline { 3 - 5 } & & $\mathbf{2 5 \%}$ & $\mathbf{5 0 \%}$ & $\mathbf{7 5 \%}$ & & & \\
\hline $\mathrm{PM}_{10}\left(\mathrm{ug} / \mathrm{m}^{3}\right)$ & 14.26 & 34.89 & 46.83 & 62.37 & 888.02 & 51.71 & 1,826 \\
$\mathrm{PM}_{2.5}\left(\mathrm{ug} / \mathrm{m}^{3}\right)$ & 8.35 & 19.46 & 27.06 & 36.92 & 140.54 & 29.99 & 1,826 \\
$\mathrm{SO}_{2}(\mathrm{ppb})$ & 1.00 & 2.73 & 3.65 & 4.91 & 11.14 & 3.94 & 1,826 \\
$\mathrm{NO}_{2}(\mathrm{ppb})$ & 3.22 & 19.97 & 23.86 & 28.81 & 55.59 & 24.67 & 1,826 \\
$\mathrm{CO}(\mathrm{ppm})$ & 0.13 & 0.50 & 0.63 & 0.80 & 1.76 & 0.68 & 1,826 \\
$\mathrm{O}_{3}(\mathrm{ppb})$ & 4.00 & 17.95 & 23.95 & 30.23 & 70.89 & 24.65 & 1,826 \\
Temperature $\left({ }^{\circ} \mathrm{C}\right)$ & 9.35 & 19.50 & 24.11 & 28.42 & 33.18 & 23.69 & 1,826 \\
Humidity $(\%)$ & 31.37 & 66.54 & 73.11 & 79.57 & 94.19 & 72.82 & 1,826 \\
COPD admissions & 0 & 9 & 12 & 15 & 30 & 12.28 & 1,826 \\
\hline
\end{tabular}

Abbreviation: Min, minimum value; Max, maximum value; ${ }^{a} 24 \mathrm{~h}$ average.

Table 2. Correlation coefficients among air pollutants.

\begin{tabular}{ccccccc}
\hline Variable & $\mathbf{P M}_{\mathbf{1 0}}$ & $\mathbf{P M}_{\mathbf{2 . 5}}$ & $\mathbf{S O}_{\mathbf{2}}$ & $\mathbf{N O}_{\mathbf{2}}$ & $\mathbf{C O}$ & $\mathbf{O}_{\mathbf{3}}$ \\
\hline $\mathrm{PM}_{10}$ & 1.0 & 0.78 & 0.43 & 0.35 & 0.35 & 0.26 \\
$\mathrm{PM}_{2.5}$ & - & 1.0 & 0.61 & 0.54 & 0.54 & 0.31 \\
$\mathrm{SO}_{2}$ & - & - & 1.0 & 0.52 & 0.50 & 0.06 \\
$\mathrm{NO}_{2}$ & - & - & - & 1.0 & 0.89 & -0.07 \\
$\mathrm{CO}$ & - & - & - & - & 1.0 & -0.23 \\
$\mathrm{O}_{3}$ & - & - & - & - & - & 1.0 \\
\hline
\end{tabular}

Table 3. Association between $\mathrm{PM}_{2.5}$ and admissions for COPD in Taipei, Taiwan, 2006-2010.

\begin{tabular}{ccc}
\hline Temperature & PM $_{2.5}$ OR (95\% CI) \\
\hline & Without adjustment $^{\mathrm{b}}$ & $1.12(1.08-1.16)$ \\
$\geq 23{ }^{\circ} \mathrm{C}(1,021$ days $)$ & Adjusted for $\mathrm{SO}_{2}$ & $1.14(1.09-1.19)$ \\
& Adjusted for $\mathrm{NO}_{2}$ & $1.02(0.97-1.07)$ \\
& Adjusted for $\mathrm{CO}$ & $1.01(0.96-1.05)$ \\
& Adjusted for $\mathrm{O}_{3}$ & $1.12(1.08-1.17)$ \\
& Without adjustment $^{\mathrm{b}}$ & $1.03(1.00-1.07)$ \\
& Adjusted for $\mathrm{SO}_{2}$ & $1.12(1.07-1.17)$ \\
& Adjusted for $\mathrm{NO}_{2}$ & $0.97(0.94-1.01)$ \\
& Adjusted for $\mathrm{CO}^{\circ}(805$ days $)$ & $1.02(0.98-1.06)$ \\
& Adjusted for $\mathrm{O}_{3}$ & $1.04(1.01-1.08)$ \\
\hline
\end{tabular}

a Calculated for an interquartile range increases of $\mathrm{PM}_{2.5}\left(17.46 \mathrm{ug} / \mathrm{m}^{3}\right)$ and adjusted for temperature and humidity;

${ }^{\mathrm{b}}$ Single pollutant model.

\section{Conclusions}

In summary, this study provided evidence of associations between short-term exposure to $\mathrm{PM}_{2.5}$ and increased hospital admissions for COPD. 


\section{Acknowledgments}

This study is based in part on data from the National Insurance Research Database provided by the Bureau of National Health Insurance, Department of Health and managed by National Health Research Institutes. The interpretation and conclusions contained herein do not represent those of Bureau of National Health Insurance, Department of Health or National Health Research Institutes. This study was supported by National Health Research Institutes (EO-101-PP-08) and National Science Council (NSC-100-2314-B-037-023-MY2).

\section{Conflicts of Interest}

The authors declare no conflict of interest.

\section{References}

1. Levy, J.I.; Hammitt, J.K.; Spengler, J.D. Estimating the mortality impacts of particulate matter: What can be learned from between-study variability? Environ. Health Perspect. 2000, 108, 109-117.

2. Pope, C.A., III; Burnett, R.T.; Thurston, G.D.; Thun, M.J.; Calle, E.E.; Krewski, D.; Godleski, J.J. Cardiovascular mortality and long-term exposure to particulate air pollution: Epidemiological evidence of general pathophysiological pathways of disease. Circulation 2004, 109, 71-77.

3. Goodman, P.G.; Dockery, D.W.; Clancy, L. Cause-specific mortality and the extended effects of particulate pollution and temperature exposure. Environ. Health Perspect. 2004, 112, 179-185.

4. Schwartz, J. The effects of particulate air pollution on daily deaths: A multi-city case-crossover analysis. Occup. Environ. Med. 2004, 61, 956-961.

5. Analitis, A.; Katsouyanni, K.; Dimakopoulou, K.; Samoli, E.; Nikoloulopoulos, A.K.; Petasakis, Y.; Touloumi, G.; Schwartz, J.; Anderson, H.R.; Cambra, K.; et al. Short-term effects of ambient particles on cardiovascular and respiratory mortality. Epidemiology 2006, 17, 230-233.

6. Air quality guidelines-Global update 2005. Available online: http://www.who.int/phe/ health_topics/outdoorair/outdoorair_aqg/en/index.html (accessed on 6 November 2013).

7. Cohen, A.J.; Anderson, H.R.; Ostro, B.; Pandey, K.D.; Krzyzanowsli, M.; Kunzli, N.; Gutschmidt, K.; Pope, A.; Romieu, I.; Samet, J.M.; Smith, K. The global burden of disease due to outdoor air pollution. J. Toxicol. Environ. Health Part A 2005, 68, 1301-1307.

8. Samet, J.; Krewski, D. Health effects associated with exposure to ambient air pollution. J. Toxicol. Environ. Health Part A 2007, 70, 227-242.

9. Zanobetti, A.; Schwartz, J.; Dockery, D.W. Airborne particles are a risk factor for hospital admissions for heart and lung disease. Environ. Health Perspect. 2000, 108, 1071-1077.

10. Le Tertre, A.; Medina, S.; Samoli, E.; Forsberg, B.; Michelozzi, P.; Boumghar, A.; Vonk, J.M.; Bellini, A.; Atkinson, R.; Ayres, J.G.; Sunyer, J.; et al. Short-term effects of particulate air pollution on cardiovascular diseases in eight European cities. J. Epidemiol. Community Health 2002, 56, 773-779.

11. Bedeschi, E.; Campari, C.; Candela, S.; Collini, G.; Caranci, N.; Frasca, G.; Galassi, C.; Francesca, G.; Vigotti, M.A. Urban air pollution and respiratory emergency visits at pediatric unit, Reggio Emilia, Italy. J. Toxicol. Environ. Health Part A 2007, 70, 261-265. 
12. Krewski, D.; Burnett, R.; Jerrett, M.; Pope, C.A.; Rainham, D.; Calle, E.; Thurston, G.; Thun, M. Mortality and long-term exposure to ambient air pollution: Ongoing analyses based on the American Cancer Society cohort. J. Toxicol. Environ. Health Part A 2005, 68, 1093-1109.

13. Dominici, F.; Peng, R.D.; Bell, M.L.; Pham, L.; McDermott, A.; Zeger, S.L.; Samet, J.M. Fine particulate air pollution and hospital admission for cardiovascular and respiratory diseases. J. Am. Med. Assoc. 2006, 295, 1127-1134.

14. Craig, L.; Brook, J.R.; Chiotti, Q.; Croes, B.; Gower, S.; Hedley, A.; Krewski, D.; Krupnick, A.; Krzyzanowski, M.; Moran, M.D.; et al. Air pollution and public health: A guide document for risk managers. J. Toxicol. Environ. Health Part A 2008, 71, 588-698.

15. Cifuentes, L.A.; Vega, J.; Kopfer, K.; Lave, L.B. Effect of the fine fraction of particulate matter versus the coarse mass and other pollutants on daily nortality in Santiago Chile. J. Air Waste Manage. Assoc. 2000, 50, 1287-1298.

16. Schwartz, J.; Dockery, D.W.; Neas, L.M. Is daily mortality associated specifically with fine particles? J. Air Waste Manage. Assoc. 1996, 46, 927-939.

17. Zanobetti, A.; Franklin, M.; Koutrakis, P.; Schwartz, J. Fine particulate air pollution and its components in association with cause-specific emergency admissions. Environ. Health 2009, 8, 58, doi:10.1186/1476-069X-8-58.

18. Liao, D.; Shaffer, M.L.; He, F.; Rodriguez-Colon, S.; Wu, R.; Whitsel, E.A.; Bixler, E.O.; Cascio, W.E. Fine particulate air pollution is associated with higher vulnerability to atrial fibrillation-the Apacr study. J. Toxicol. Environ. Health Part A 2011, 74, 693-705.

19. Wilson, W.E.; Suh, H.H. Fine particles and coarse particles: Concentration relationship relevant to epidemiologic studies. J. Air Waste Manage. Assoc. 1997, 47, 1238-1249.

20. Pope, C.A., III; Dockery, D.W. Health effects of fine particulate air pollution: Lines that connect. J. Air Waste Manage. Assoc. 2006, 56, 709-742.

21. Host, S.; Larrieu, S.; Pascal, L.; Blanchard, M.; Declercq, C.; Fabre, P.; Jusot, J.-F.; Chardon, B.; le Tertre, A.; Wagner, V.; et al. Short-term associations between fine and coarse particles and hospital admissions for cardiorespiratory diseases in six French cities. Occup. Environ. Med. 2008, 65, 544-551.

22. Bell, M.L.; Ebisu, K.; Peng, R.D.; Walker, J.; Samet, J.M.; Zeger, S.L.; Dominici, F. Seasonal and regional short-term effects of fine particles on hospital admissions in 202 US counties, 1999-2005. Am. J. Epidemiol. 2008, 168, 1301-1310.

23. Halonen, J.I.; Lanki, T.; Yli-Tuomi, T.; Tiittanen, P.; Kulmala, M.; Pekkanen, J. Particulate air pollution and acute cardiorespiratory hospital admissions and mortality among the elderly. Epidemiology 2009, 20, 143-153.

24. Peng, R.D.; Bell, M.L.; Geyh, A.S.; McDermott, A.; Zeger, S.L.; Samet, J.M.; Dominici, F. Emergency admissions for cardiovascular and respiratory diseases and the chemical composition of fine particle air pollution. Environ. Health Perspect. 2009, 117, 957-963.

25. Linares, C.; Diaz, J. Short-term effect of concentrations of fine particulate matter on hospital admissions due to cardiovascular and respiratory causes among the over-75 age group in Madrid, Spain. Public Health 2010, 124, 28-36. 
26. Medina-Ramon, M.; Zanobetti, A.; Schwartz, J. The effect of ozone and $\mathrm{PM}_{10}$ on hospital admissions for pneumonia and chronic obstructive pulmonary disease: A national multicity study. Am. J. Epidemiol. 2006, 163, 579-588.

27. Halonen, J.I.; Lanki, T.; Yli-Tuomi, T.; Kulmala, M.; Tiittanen, P.; Pekkanen, J. Urban air pollution and asthma and COPD hospital emergency room visits. Thorax 2008, 63, 635-641.

28. Belleudi, V.; Faustini, A.; Stafoggia, M.; Cattani, G.; Marconi, A.; Perucci, C.A.; Forastiere, F. Impact of fine and ultrafine particles on emergency hospital admissions for cardiac and respiratory diseaes. Epidemiology 2010, 21, 414-423.

29. Hinwood, A.L.; de Klerk, N.; Rodriguez, C.; Jacoby, P.; Runnion, T.; Rye, P.; Landau, L.; Murray, F.; Feldwick, M.; Spickett, J. The relationship between changes in daily air pollution and hospitalizations in Perth, Australia 1992-1998: A case-crossover study. Int. J. Environ. Health Res. 2006, 16, 27-46.

30. Chen, Y.; Yang, Q.; Krewski, D.; Shi, Y.; Burnett, R.T.; McGrail, K. Influence of relatively low level of particulate air pollution on hospitalization for COPD in elderly people. Inhal. Toxicol. 2004, 16, 21-25.

31. Yang, C.-Y.; Chang, C.-C.; Chuang, H.-Y.; Tsai, S.-S.; Wu, T.-N.; Ho, C.-K. Relationship between air pollution and daily mortality in a subtropical city: Taipei, Taiwan. Environ. Int. 2004, 30, 519-523.

32. Yang, C.-Y.; Chen, C.-C.; Chen, C.-Y.; Kuo, H.-W. Air pollution and hospital admissions for asthma in a subtropical city: Taipei, Taiwan. J. Toxicol. Environ. Health Part A 2007, 70, 111-117.

33. Yang, C.-Y. Air pollution and hospital admissions for congestive heart failure in a subtropical city: Taipei, Taiwan. J. Toxicol. Environ. Health Part A 2008, 71, 1085-1090.

34. Hsieh, Y.-L.; Yang, Y.-H.; Wu, T.-N.; Yang, C.-Y. Air pollution and hospital admissions for myocardial infarction in a subtropical city: Taipei, Taiwan. J. Toxicol. Environ. Health Part A 2010, 73, 757-765.

35. Chang, C.-C.; Tsai, S.-S.; Ho, S.-C.; Yang, C.-Y. Air pollution and hospital admissions for cardiovascular disease in Taipei, Taiwan. Environ. Res. 2005, 98, 114-119.

36. Chiu, H.-F.; Cheng, M.-H.; Yang, C.-Y. Air pollution and hospital admissions for pneumonia in a subtropical city: Taipei, Taiwan. Inhal. Toxicol. 2009, 21, 32-37.

37. Chang, C.-C.; Kuo, C.-C.; Liou, S.-H.; Yang, C.-Y. Fine particulate air pollution and hospital admissions for myocardial infarction in a subtropical city: Taipei, Taiwan. J. Toxicol. Environ. Health Part A 2013, 76, 440-448.

38. Chiu, H.-F.; Tsai, S.-S.; Weng, H.-H.; Yang, C.-Y. Short-term effects of fine particulate air pollution on emergency room visits for cardiac arrhythmias: A case-crossover study in Taipei. J. Toxicol. Environ. Health Part A 2013, 76, 614-623.

39. Hsieh, Y.-L.; Tsai, S.-S.; Yang, C.-Y. Fine particulate air pollution and hospital admissions for congestive heart failure: A case-crossover study in Taipei. Inhal. Toxicol. 2013, 25, 455-460.

40. Hung, L.-J.; Tsai, S.-S.; Chen, P.-S.; Yang, Y.-H.; Liou, S.-H.; Wu, T.-N.; Yang, C.-Y. Traffic air pollution and risk of death from breast cancer in Taiwan: Fine particulate matter $\left(\mathrm{PM}_{2.5}\right)$ as a proxy marker. Aerosol Air Qual. Res. 2012, 12, 275-282. 
41. Hung, L.J.; Chan, T.F.; Wu, C.H.; Chiu, H.F.; Yang, C.Y. Traffic air pollution and risk of death from ovarian cancer in Taiwan: Fine particulate matter $\left(\mathrm{PM}_{2.5}\right)$ as a proxy marker. J. Toxicol. Environ. Health Part A 2012, 75, 174-182.

42. Maclure, M. The case-crossover design: A method for studying transient effects on the risk of acute events. Am. J. Epidemiol. 1991, 133, 144-153.

43. Marshall, R.J.; Jackson, R.T. Analysis of case-crossover designs. Stat. Med. 1993, 12, 2333-2341.

44. Mittleman, M.A.; Maclure, M.; Robins, J.M. Control sampling strategies for case-crossover studies: An assessment of relative efficiency. Am. J. Epidemiol. 1995, 142, 91-98.

45. Levy, D.; Lumley, T.; Sheppard, L.; Kaufman, J.; Checkoway, H. Referent selection in case-crossover analyses of acute health effects of air pollution. Epidemiology 2001, 12, 186-192.

46. Lee, J.T.; Schwartz, J. Reanalysis of the effects of air pollution on daily mortality in Seoul, Korea: A case-crossover design. Environ. Health Perspect. 1999, 107, 633-636.

47. Lu, Y.; Zeger, S.L. On the equivalence of case-crossover and time series methods in environmental epidemiology. Biostatistics 2007, 8, 337-344.

48. Neas, L.M.; Schwartz, J.; Dockery, D. A case-crossover analysis of air pollution and mortality in Philadelphia. Environ. Health Perspect. 1999, 107, 629-631.

49. Lumley, T.; Levy, D. Bias in the case-crossover design: Implications for studies of air pollution. Environmetrics 2000, 11, 689-704.

50. Janes, H.; Sheppard, L.; Lumley, T. Case-crossover analyses of air pollution exposure data: Referent selection strategies and their implications for bias. Epidemiology 2005, 16, 717-726.

51. Mittleman, M.A. Optimal referent selection strategies in case-crossover studies: A settled issue. Epidemiology 2005, 16, 715-716.

52. Katsouyanni, K.; Touloumi, G.; Spix, C.; Schwartz, J.; Balducci, F.; Medina, S.; Rossi, G.; Wojtyniak, B.; Sunyer, J.; Bacharova, L.; et al. Short-term effects of ambient sulphur dioxide and particulate matter on mortality in 12 European cities: Results from time series data from the APHEA project. Air pollution and health: A European approach. Br. Med. J. 1997, 314, 1658-1663.

53. Brunekreef, B.; Holgate, S.T. Air pollution and health. Lancet 2002, 360, 1233-1242.

54. Ghio, A.J.; Carraway, M.S.; Madden, M.C. Composition of air pollution particles and oxidative stress in cells, tissues, and living systems. J. Toxicol. Environ. Health Part B 2012, 15, 1-21.

55. MacNee, W.; Donaldson, K. Mechanisms of lung injury caused by $\mathrm{PM}_{10}$ and ultrafine particles with special references to COPD. Eur. Respir. J. 2003, 21, 47s-51s.

56. Costa, D.L.; Dreher, K.L. Bioavailable transition metals in particulate matter mediate cardiopulmonary injury in healthy and compromised animal models. Environ. Health Perspect. 1997, 105, 1053-1060.

57. Zelikoff, J.T.; Chen, L.C.; Cohen, M.D.; Fang, K.; Gordon, T.; Li, Y.; Nadziejko, C.; Schlesinger, R.B. Effects of inhaled ambient particulate matter on pulmonary antimicrobial immune defense. Inhal. Toxicol. 2003, 15, 131-150.

58. Suh, H.H.; Zanobetti, A.; Schwartz, J.; Coull, B.A. Chemical properties of air pollutants and cause-specific hospital admissions among the elderly in Atlanta, Georgia. Environ. Health Perspect. 2011, 119, 1421-1428. 
59. Schwartz, J.; Marcus, A. Mortality and air pollution in London: A time series analysis. Am. J. Epidemiol. 1990, 131, 185-194.

60. Zeger, S.L.; Thomas, D.; Dominici, F.; Samet, J.M.; Schwartz, J.; Dockery, D.; Cohen, A. Exposure measurement error in time-series studies of air pollution: Concepts and consequences. Environ. Health Perspect. 2000, 108, 419-426.

(C) 2013 by the authors; licensee MDPI, Basel, Switzerland. This article is an open access article distributed under the terms and conditions of the Creative Commons Attribution license (http://creativecommons.org/licenses/by/3.0/). 